\title{
O QUE SE FAZ EM UMA AULA DE HISTÓRIA? PENSAR SOBRE A COLONIALIDADE DO TEMPO
}

\author{
WHAT DO YOU DO IN A HISTORY CLASS? THINK ABOUT THE \\ COLONIALITY OF TIME \\ ¿QUÉ SE HACE EN UNA CLASE DE HISTORIA? PENSAR SOBRE LA \\ COLONIALIDAD DEL TIEMPO
}

Nilton Mullet Pereira niltonmp.pead@gmail.com

\author{
REVISTA PEDAGÓGICA \\ Revista do Programa de Pós-graduação em Educação da Unochapecó | ISSN 1984-1566 \\ Universidade Comunitária da Região de Chapecó | Chapecó-SC, Brasil \\ Como referenciar este artigo: PEREIRA, N. M. O que se faz em uma aula de História? Pensar sobre \\ a colonialidade do tempo. Revista Pedagógica, Chapecó, v. 20, n. 45, p. 16-35, set./dez. \\ DOI: http://dx.doi.org/10.22196/rp.v20i45.4512
}

RESUMO: O presente artigo apresenta uma discussão teórica sobre as relações entre a aula de História, o ensino de História e a colonialidade do tempo. Propõe o debate acerca do papel do tempo na aula e no ensino de História, a partir da problematização do pensamento decolonial, especificamente do pensador Anibal Quijano, em diálogo com autores da filosofia da diferença, como Nietzsche, Bergson, Deleuze e Foucault. Tal problematização permitiu a criação do conceito de colonialidade do tempo, para a partir dele, pensar o que se faz no ensino de História e o que se faz em uma aula de História, na perspectiva de propor repensar esses dois espaços, o primeiro tomado como lugar de produção conceitual e criação de formas expressivas para os conceitos históricos e a segunda como o Caos genético, por onde desfilam diferentes saberes e temporalidades. Desse modo, o rompimento com a colonialidade do tempo está relacionado a pensar a hesitação e a abertura como formas de criar experiências com o outro, sem reduzi-lo a uma narrativa que estabelece os limites sobre como medir, representar e experienciar o tempo.

Palavras-chave: Colonialidade do tempo. Aula de História. Ensino de História. Narrativa.

ABSTRACT: This study presents a theoretical discussion about the relations between History class, History teaching and coloniality of time. It proposes a debate about the role of time in the class and teaching of History through the problematization of the decolonial thinking, specifically of the thinker Anibal Quijano, in a dialogue with authors of the philosophy of difference, such as Nietzsche, Bergson, Deleuze and Foucault. This problematization allowed creating the concept of coloniality of time, for thinking, through this notion, about what is done in History teaching and what is done in a History class, aiming to propose rethinking these two spaces, the first taken as a conceptual production and creation of expressive forms for historical concepts, and the second as the genetic Chaos, on which different backgrounds and temporalities strut. Thus, the disruption with the coloniality of time is related to the vision of hesitation and openness as ways to create experiences with the other, without limiting it to a narrative establishing the limits about how to measure, represent and experience time.

Keywords: Coloniality of time. History class. History teaching. Narrative.

RESUMEN: Este artículo presenta una discusión teórica sobre las relaciones entre la clase de Historia, la enseñanza de la historia y la colonialidad del tiempo. Propone, también, un debate sobre el papel del tiempo en el aula y en la enseñanza de la historia, desde el cuestionamiento del pensamiento colonialista, específicamente el pensador Aníbal Quijano, en diálogo con autores de la filosofía de la diferencia, como Nietzsche, Bergson, Deleuze y Foucault. Tal cuestionamiento permitió la creación del concepto de colonialidad del tiempo, para, a partir de ello, pensar lo que se hace en la enseñanza de la historia y lo que se hace en una clase de Historia, en la perspectiva repensar esos dos espacios, el primero tomado como lugar de producción conceptual y creación de formas expresivas para los conceptos históricos, y la segunda como el Caos genético, por donde desfilan diferentes saberes y temporalidades. De este modo, el rompimiento con la colonialidad del tiempo está relacionado a pensar la vacilación y la apertura como formas de crear experiencias con el otro, sin reducirlo a una narrativa que establece los límites sobre cómo medir, representar y experimentar el tiempo.

Palabras clave: Colonialidad del tiempo. Clase de historia. Enseñanza de la historia. Narrativa. 


\section{Início por uma cena}

O início da aula pareceu descontraído, conversas desinteressadas e dispersivas, criando um clima agradável e amigável entre professor e alunos. Uma vez que estavam todos sentados e o professor diante do quadro verde, iniciou-se o percurso daquela aula, que, de tão exemplar, acabou por fazer parte deste espaço onde procuro pensar o ensino e a aula de História. O tema era o Renascimento , uma das mais duradouras ficções criadas pela História, que foi apresentada pelo professor sem percalços, dúvidas ou hesitação - guardemos esta última palavra; ela será importante, tanto do ponto de vista do conteúdo apresentado, o Renascimento, quanto do ponto de vista do modo de expressão utilizado para sua apresentação.

Vamos começar com o modo de expressão: os caminhos daquela aula parece terem sido construídos em uma grande avenida ampla e reta, uma linha que se iniciava com Leonardo da Vince e terminava com Giordano Bruno. Era uma linha, sem dúvida, lisa, sem estrias, sem curvas, sem esquinas perigosas que pudessem criar uma certa sensação de medo ou angústia. Primeiro, o professor pintou no quadro, com uma caneta azul, uma linha de tempo, onde se podia notar uma divisão da história entre o ano 300 a.C. e os dias de hoje. Onde ele escreveu "Idade Moderna", fez também uma seta que indicava o momento no qual ocorreu o chamado Renascimento. Abaixo, escreveu um pequeno esquema, onde apareciam as principais personagens, obras e características do período, das quais a mais citada era o humanismo. Depois, o professor colocou em prática sua narrativa histórica, explicando as ideias de alguns dos pensadores do período, o que se realizou em pouco mais de 15 minutos. A narrativa era precisa, sem desvios e sem provocações, sem perguntas, sem enganos possíveis, sem qualquer abertura para questionamentos dos alunos, muito menos sem provocações propositais do professor. Poucas vezes pude presenciar tamanha quantidade de certezas em uma narrativa, as quais eram expostas através da maneira como foi realizada a narração. De tão certa de suas verdades no modo definido e liso como se construía diante dos alunos, aquela narrativa não deixava dúvidas, não incitava a imaginação sobre os séculos XVI ou XVII, nem mesmo sugeria, através de estratégias retóricas, uma aproximação com os ouvintes. Era uma narrativa no tempo presente. O quadro habitado pelo esquema, os alunos dispostos quietos em suas classes e a voz do professor que saia em um tom suave, até, mas sem relevos acidentados que pudessem lhe fazer duvidar de si mesma. Era o império do presente que ali se levantava, deixando cada um e todos em um só tempo - o da redução da narrativa, ele o presente, atual e tão real quanto pudesse ser matéria formada e cristalizada. O efeito mais cruel é que os alunos talvez estivessem pouco dispostos a imaginar, a realizar a viagem no tempo de que tanto se fala quando se aprende História. 
1 A cena descrita foi construída a partir de fragmentos da minha própria experiência como professor de um oitavo ano, onde ensinei o Renascimento Cultural por 13 anos.
Mas, vamos ao conteúdo, o conhecimento, o reconhecimento: o conteúdo era um punhado de afirmações sobre o Renascimento. Em torno do relato ali criado sobre o passado europeu, nenhuma outra força parecia transitar senão a da narrativa, que desqualificava o que pudesse fazê-la duvidar de si mesma, entrar em choque e, quem sabe, desviar da linha que se traçou para apresentar $e$ constituir uma forma notadamente europeia, branca, moderna, evolucionista e progressivista: o Renascimento. A exposição sobre o tema em questão não trazia em si a potência de poder ser diferente, de se autodestruir, de se autodesidentificar consigo mesma ao ponto de se deixar levar por forças estranhas e transformadoras. Se tal narrativa se deixasse levar pelo movimento "neutro" das forças, o professor poderia, por exemplo, questionar a ideia de renascimento, a ideia de ciência e, então, pensar sobre como pôde se construir uma ficção tão poderosa com essa, que consiste em supor que houve um renascimento e que ele indica um progresso e uma evolução em relação à "obscura" Idade Média. O professor não perguntou ao seus alunos: "E se já existisse ciência na Idade Média?"; "O que é ciência?"; "A ideia de Renascimento não carrega em si uma noção temporal que sustenta, desde essa mesma época, a hierarquização das sociedades e dos povos do mundo em mais ou menos evoluídos?"; "E se essa noção temporal estiver intimamente relacionada ao racismo?"; "Imaginem se rompêssemos, de repente, com essa noção de que há hierarquia entre os povos em função da ideia de progresso e de evolução, como nos relacionaríamos hoje com os nossos outros humanos?”.

Voltemos àquela palavra: hesitação. O que aconteceu em aula? $O$ desenho acabado de uma prisão. $O$ encarceramento pela narrativa. Ela deslizou pela linha reta, em um modo de expressão destinado a se tornar tão habitual quanto tudo o que ocorre sem qualquer hesitação, um conhecimento repisado, sem abertura para as forças da imaginação e do tempo. Não houve, nem por um breve instante, hesitação diante dos dados do presente ou das formas do presente, o que lhe permitiria experimentar o jorro do tempo e o turbilhão de forças inatuais que podem criar novidades. Não houve espaço para os não dados da imaginação. Aquela aula seguiu como um ponto material onde se sustenta a colonialidade do tempo. É dela que quero tratar agora. ${ }^{1}$

\section{Introdução}

A escrita deste artigo nasce de uma inocência (NIETZSCHE, 1989) diante das coisas: tais como a linha do tempo, a cronologia, a História, o ensino de História, a aula de História. Essa inocência funciona como uma leveza frente a essas incríveis e poderosas estruturas que constituem modelos explicativos, padrões de comportamento e formas de medir o tempo. É, portanto, a inocência que me faz manter 
2 Mais adiante, este artigo discute em que consiste o atual e o virtual. Por enquanto, é necessário afirmar que tal concepção deriva de uma captura que Deleuze (1996) realiza de Bergson, consistindo o atual no que é formal, que tem existência presente e material, enquanto o que é virtual é informal, constitui-se em um campo de forças ainda não atualizadas. um tanto de perplexidade e, ao mesmo tempo, angústia diante dessas formas que têm me acompanhado no ensino e na pesquisa. A inocência é a liberdade do espírito que embala o pensamento e a criação, não sem uma incrível porção de indignação. A inocência me leva ao esquecimento e a ter um poder de surpresa que o mundo das matérias formadas já não pode mais me fornecer. É partir dessa inocência e perplexidade que escrevo este artigo, realizando um diálogo tenso, porém colaborativo, entre diferentes autores que se situam no lado oposto dos processos de padronização da temporalidade, do progresso e da evolução. O encontro com o pensamento desses autores me leva a torcer seus conceitos para o interior da duração da minha escrita, de um modo que não esconde minhas intenções, mas cria diálogos talvez improváveis. Tais torções se iniciam com Anibal Quijano e a colonialidade do poder (2005), pois o argumento inicial consiste na noção de que vivemos em uma temporalidade colonizada - daí a ideia de uma colonialidade do tempo, um conjunto articulado de enunciados de diversos tipos e que aparecem em inúmeros lugares de enunciação, que constroem uma estrutura sólida e quase inquebrantável, aparentando ser um dado da natureza, definindo o modo como nos relacionamos com o tempo. São construções ficcionais poderosas que têm criado um campo vasto para a experiência humana, associando sistematicamente e de modo imperceptível o tempo às formas de medi-lo, de representá-lo e de experienciá-lo - formas que são particulares, contingentes e históricas, mas que se apresentam como naturais e universais à medida que se fazem coincidir com o próprio tempo.

A partir dessa noção que se sustenta no diálogo com Quijano, penso que o ensino de História está diante de um desafio limite, de difícil transfiguração: como ultrapassar os limites impostos pela colonialidade do tempo. Assim, minha intenção é problematizar o que faz o ensino de História e como seria possível supor uma aula de História sem as fronteiras estabelecidas, desde o século XIX, por uma temporalidade colonizada.

A colonialidade do tempo torna o ensino e a aula de História pontos materiais de enunciação e estruturas formais a partir das quais esse "padrão de poder" se consolida e se dá em continuidade. O que quero estudar é como o ensino e a aula de História podem se constituir em lugares de resistência ao poder colonial e à colonialidade do tempo. Nesse sentido, tanto o ensino quanto a aula de História são vistos como complexos de atuais e de virtuais ${ }^{2}$ que se deixam torcer para se transfigurarem e ultrapassarem limites.

Por ensino de História, quero dizer um campo de produção conceitual, desde a produção de conceitos para pensar a aula de História e a aprendizagem histórica até o desenvolvimento de modos de expressão para inserir, no interior de um espaço onde se aprende História, tais conceitos. A aula de História considero como um complexo por onde transitam saberes, memórias, fazeres, narrativas e 
3 Experiência na acepção bergsoniana, que se volta à duração em vez de se deixar levar pelos pontos de parada que definem os limites cronológicos para a vida. A experiência, no bergsionismo, está intimamente relacionada à energia vital (BERGSON, 2005) e criadora. Perbart nos permite pensar, mediante Bergson, em uma experiência que se dá como relação com um movimento perpétuo de energia e forças. "A vida é uma tendência que cria direções divergentes, dissociando-se e diferenciando-se, é um princípio de indeterminação introduzido na matéria. A essência da vida estaria no movimento pelo qual ela é transmitida, no seu caráter germinal, na sua atualização, nisso que Bergson chamou de evolução criadora. Tal evolução seria como uma dissociação do fluxo contínuo da duração e dos limites estabelecidos (espécies), a vida seria como uma acumulação de energia e a canalização dessa energia em direções indeterminadas - uma lenta acumulação, descarga súbita -, e as formas vivas seriam como veículos através dos quais o impulso vital descarrega sua energia e se reorganiza para invenções e criações futuras. Bergson não é um finalista, é um virtualista" (PELBART, 2011, p.74).
Histórias, que permite o acesso a diversos modos de pensar o tempo, a realidade, o passado e o presente. Ela constitui, no seu interior, um excesso que a torna lugar de criação de novos modos de representar o tempo e de experienciar a vida - uma aula como lugar de experiência ${ }^{3}$, como lugar improvável para deixar fluir uma nova e imprevisível relação com o passado.

É neste momento que ocorre a torção do pensamento de outros autores: o Caos, como caráter geral da natureza, de Nietzsche (2001); o Atual e o Virtual, de Bergson e Deleuze (1996); o Fora, de Michel Foucault (2009). A partir de - e em diálogo com - esses conceitos principais, procuro imaginar um ensino e uma aula de História que possam ser decolonizados. O ponto de partida é, sobretudo, Anibal Quijano e o movimento decolonial. Em diálogo com ele, os autores referidos anteriormente criam o clima de crítica e de transfiguração da moderna noção de tempo, que tem servido para um doloroso processo de colonialidade. Aqui, se destaca o diálogo da produtividade dos autores europeus que romperam com o modelo de modernidade arquitetado pelo eurocentrismo com o autor latino-americano que pensa a partir deste lugar onde nos encontramos.

Quijano definiu colonialidade como um "novo padrão de poder mundial" que teria emergido no colonialismo europeu dos séculos XV e XVI e se estende aos dias de hoje. Esse poder consiste no estabelecimento de uma hierarquia entre os povos, em caráter mundial, determinando relações de trabalho, de saber e de poder fundamentadas na categoria de raça (QUIJANO, 2014). Desse modo, o que se chamou de modernidade está intimamente ligado à colonialidade, uma vez que ela representa uma experiência social, material e subjetiva que estabeleceu a Europa iluminista como o centro a partir do qual outros povos e tempos são avaliados. Essa concepção se organiza através de duas noções centrais: o dualismo e o evolucionismo.

O dualismo criou uma visão de mundo baseada em um sistema binário e valorativo em que um dos polos tem mais valor do que o outro. Essa noção invadiu o cotidiano de tal forma que nosso modo de ser e de compreender as relações, as pessoas e os grupos passou a estar sempre limitado por essa visão dual, que estabelece uma hierarquia entre os polos do sistema: o tradicional e o moderno, o racional e o mítico, o primitivo e o civilizado, o mágico e o científico. A "versão eurocêntrica da modernidade" estabelece as diferenças entre os dois polos como diferenças de natureza, não como diferenças históricas construídas segundo as injunções do poder. O espelho eurocêntrico nos faz crer que as diferenças entre europeu e não europeu, por exemplo, são naturais, não criadas pelas relações de poder e pelo processo de colonização.

O evolucionismo, por seu turno, constitui-se de uma temporalidade que supõe o presente como o ápice de um processo, o momento mais importante, verdadeiro e, portanto, evoluído, lançando, assim, um olhar sempre 
moralizante sobre o passado, uma vez que o antigo sempre tem valor menor que o atual. O moderno é, desse modo, sinônimo de algo melhor e mais refinado. Esse é um dos aspectos mais centrais de uma colonialidade do tempo. Como nossa experiência do tempo se dá através da concepção da evolução e do progresso, tendemos a criar padrões que definem o europeu como o símbolo de uma modernidade ao passo que indígenas, africanos ou orientais são definidos como atrasados, antigos, enfim, em uma situação inferior de evolução. Essa temporalidade criou formas muito específicas de contar e medir o tempo, que foram universalizadas e naturalizadas, como, por exemplo, a cronologia e a linha do tempo.

Pensar o que faz o ensino de História, portanto, é inserir esse nosso lugar privilegiado de pensamento em um fosso profundo, a fim de que se torne objeto de uma crítica dos seus elementos mais fundantes, como o tempo e suas representações. Pensar uma colonialidade do tempo significa supor que o tempo é um privilégio, o qual foi conquistado pelos e para os brancos, a partir de um intenso processo de colonialidade do saber, do poder e da vida. Trata-se de um privilégio que se confunde com o próprio tempo e dele se apropria, tornando-o, de uma só vez, tanto próximo e particular quanto distante e exteriorizado, ao ponto de fazer com que se acredite que o modo como conta, mede e experiencia é universal e natural. Se o ensino de História é povoado pelos fantasmas da colonialidade do tempo, a aula de História pode ser um espaço aberto para experiências estranhas, fugidias, pouco afeitas à nacionalidade ou aos modos de pensar a política, a sociedade e a vida que o eurocentrismo criou.

\section{Perplexidades de um professor de História}

Um momento de hesitação me coloca a duvidar do que tenho chamado de colonialidade do tempo e de todas as ficções criadas a partir dela. Uma das mais importantes dessas ficções é a noção de uma hierarquia dos saberes, a crença da existência de um saber sábio, um saber escolar e um saber do senso comum. A consideração e o reconhecimento desses diversos níveis de saberes - o sábio, o ensinado e o do senso comum - decorre também de uma hierarquização dos diversos lugares onde atuam e agem os conceitos históricos e, ainda, demonstra um modo de pensar sobre o que acontece em uma aula de História, desde um modelo cartesiano e eurocêntrico. Me parece adequado, então, supor que tal noção realiza uma leitura moral e desqualificadora do que se faz no ensino de História e em sala de aula. Quaisquer que sejam as mediações que se realizem em relação ao que se chama de transposição didática (CHEVALLARD, 1997), a ideia de uma didatização e uma simplificação dos saberes produzidos no campo acadêmico persiste. Creio que um dos únicos modos de fugir a tal distinção e hierarquização é, justamente, não aceitar a ideia 
de que existem diferentes saberes que se relacionam ao mesmo processo criativo e, muito menos, que há uma hierarquia entre eles. A História produz conceitos, e são esses conceitos que são ensinados ou servem de operadores na escola, na universidade, nas televisões, nos debates acadêmicos, nas assembleias de trabalhadores, enfim, em qualquer espaço onde se pretenda operar ou ensinar conceitos históricos.

O que quero afirmar, de início, é que a ideia de uma relação hierárquica ou de distanciamento entre o campo da História e a aula de História implicam três delicadas operações. A primeira indica uma submissão da aula de História ao que se chama de sua ciência de referência. Trata-se de um modo de manter uma já cansativamente debatida divisão e hierarquização entre ensino e pesquisa. Se o ensino de História é um lugar onde se pensa o que acontece em uma aula de História e em uma série de outros espaços onde acontece aprendizagem histórica, a aula de História é muito mais do que apenas a História (ciência de referência): ela é sempre excesso em relação a esta. A segunda operação diz respeito à suposição de que o que se faz em uma aula de História consiste na História ensinada, ou seja, em um saber autônomo e específico que se diferencia dos conceitos criados pela História, mas, justamente, os conceitos apresentados em uma aula são justamente aqueles produzidos no âmbito da historiografia, obviamente, levados a efeito através de modos de expressão singulares àquele lugar de enunciação. A terceira operação - e, sem dúvida, a mais engenhosa - está relacionada ao fato de que uma discussão sobre o tipo de saber envolvido no ensino de História é sempre uma discussão limitada pelas fronteiras da temporalidade, que se vale e se justifica ainda pela noção de ciência e epistemologia inteiramente europeias, daí ser essa uma poderosa ficção criada no interior de uma colonialidade do tempo.

O que quero argumentar é que, em primeiro lugar, não há um saber escolar de História. O que há é a História sendo ensinada em um lugar determinado de enunciação, onde partilha experiências com outros saberes - das memórias, dos fazeres, do cotidiano, da própria escola. É sempre assim que os conceitos históricos são divulgados, apresentados ou debatidos. Se a ideia de um saber escolar de História fosse aceitável, teríamos que falar de um saber jornalístico histórico, um saber universitário da História, um saber das palestras sobre História, e por aí afora. Ou seja, a História é um campo de produção conceitual para operar compreensões sobre o passado, e são os conceitos assim produzidos que ensinamos na escola, apresentamos em programas de rádio ou ensinamos na disciplina de História medieval em um curso de graduação. Cada um desses lugares de enunciação terá suas especificidades, cada um fará os conceitos históricos entrarem em um processo de negociação e diálogo para poderem servir a interesses específicos. E esse processo de negociação e diálogo indica 
não mais uma submissão da aula de História à História, mas uma concepção da sala de aula como um lugar múltiplo e plural, que compreende que a vida é sempre excesso em relação ao que dela dizemos, que o próprio passado é sempre excesso em relação ao que dele narramos. Consequentemente, a aula de História vive esse excesso, como se estivesse no interior de uma bruma virtual que lhe obrigasse a nunca ser somente isto ou aquilo e que, sobretudo, a torna um lugar de enunciação que flerta com o Caos, que se deixa levar pelos diversos movimentos que implicam pensar uma vida, pensar os outros e suas singularidades. Assim, nela transitam saberes dos alunos, saberes escolares das mais diversas cepas e saberes de povos os quais a História não consegue e não pode narrativizar, além dos conceitos históricos. A maneira como esses conceitos podem fazer diferença na vida de cada um dos estudantes e professores é justamente sua abertura para a negociação e para um diálogo puro com as outras imagens que por ali transitam.

Para a questão sobre o que faz o ensino de História, a resposta poderia ser simples: ele atualiza o passado e o torna presente, constitui um conjunto de conceitos que determinam lugares, estados de coisas, nomes, formalidades, estruturas, conjunturas, contextos. A História e seu ensino na escola, é verdade, produzem "antropomorfismos estéticos" (NIETZSCHE, 2001, §109) que doam ao mundo algo que não é dele: formas, beleza, feiura, bem e mal. Isso porque o caráter geral do mundo, da natureza, é o Caos - nele, não há bem e mal, certo e errado. A História e o ensino de História criam tais antropomorfismos e os impõem ao mundo, desnaturalizando a natureza e a humanizando ao determinarem causas, identificarem heróis, definirem conceitos para dar sentido ao passado e construírem narrativas a partir de vestígios, fragmentos, documentos. Assim, tentam produzir um enredo plausível, compreensível, explicável, que "faça sentido" para os alunos e para as pessoas em geral a partir desses elementos que não têm um sentido em si, cuja natureza é fragmentária - a colagem, o esboço e a intriga são construídos pelos historiadores e professores de História. Ao elaborarmos e apresentarmos uma narrativa em sala de aula, o que fazemos é construir um punhado de "antropomorfismos estéticos" - formas, coisas, nomes -, os quais impomos ao mundo, à natureza, à vida. Mas a aula de História resiste a isso, ela joga diante e com as estruturas, as conjunturas, os nomes dos heróis, e de uma série de outros que resistem igualmente à narrativização, obrigando o próprio campo do ensino de História a repensar seus recortes, sua atenção, suas formas expressivas, a fim de se abrir às forças que transitam na sala de aula.

Tomar a perplexidade como elemento gerador e criador em uma aula de História permite que ela ultrapasse até mesmo os limites da própria História e da própria historicidade das coisas. Se supormos que os mundos possíveis estão já catalogados no presente e que os futuros seriam 
determinados como desdobramentos desse presente, a criação de mundos ainda imprevisíveis somente poderia se realizar em uma fuga para outras regiões, outros tempos onde até mesmo a racionalidade histórica teria de ser contestada. Uma estratégia para isso talvez seja a de fazer cessar essa narrativa apresentada em sala de aula - que é sempre atual, sempre um processo de atualização, formalização, individuação, entregando ao mundo e ao passado figuras que lhe são estranhas, sempre pensadas no presente do tempo. A narrativa como antropomorfismo estético funciona como um processo de distanciamento entre o passado e o presente, como se aquele não pudesse coexistir com este, já que todos os povos e pessoas situados no interior dessa narrativa são sempre reduzidos à porção particular de vida que ela representa, ao sentido particular ali criado, ao nome ali dado, às causas ali estabelecidas. A narrativa é sempre menos em relação a tudo o que narra. E a narrativa histórica é, via de regra, uma disposição cronológica de um conjunto de acontecimentos, tendo geralmente como referência a história europeia.

O que estou afirmando é que esse caráter atualizador é apenas uma dimensão da aula de História e da própria História, uma outra dimensão é que uma aula de História seja capaz de promover um reencontro com a Vida, com o Passado Puro (DELEUZE, 2012), e que esse reencontro consiste exatamente em ser um modo de pensar além da prisão da narrativa e muito além da colonialidade do tempo. Essa outra dimensão da aula de História pode permitir que se suspenda, por algum tempo, toda a narrativa, sem amarrar os outros sobre os quais falamos no enredo que criamos.

É com esse espírito que tenho me perguntado também sobre outra ficção muito usada pelas aulas de História, a linha do tempo. Por que razão ainda a usamos? Por que ela parece fazer parte da natureza da disciplina de História? Por que uma disciplina sem a pretensão de ter dados de natureza, que se gaba de olhar para a historicidade de todas as coisas, usa um modo de organizar o tempo que parece natural? A linha do tempo tem se imposto para professores, historiadores e pessoas em geral como uma estratégia natural de representar a passagem do tempo. Trata-se de uma representação aparentemente natural, uma representação evolucionista e linear que quase se confunde com a própria passagem do tempo, como se esta fosse capturável pela representação, como se pudesse ser narrada e coisificada. Ora, a representação que fazemos da passagem do tempo é uma maneira de frear o movimento (BERGSON, 2005). É o modo como cada povo, em determinada época, freia o movimento e dá estabilidade à experiência. O que nos faz crer que a linha do tempo e sua noção evolucionista, linear e sucessiva contém o "em si" da passagem temporal, o "em si" do tempo? Justamente um dispositivo de poder que tenho chamado de colonialidade do tempo. A linha do tempo nos engana ao sugerir que a vida é uma sucessão, que evoluímos do estado infantil ao estado adulto. Essa 
falsa impressão nos fez criar uma série de mecanismos de controle para permitir o adequado desenvolvimento das coisas até seu estado adulto. No caso específico da História, construímos uma linha que vai de um estado de natureza a um estado político que se consolida com o Estado Nacional Moderno, dando forma a uma noção de progresso que constitui, no fim das contas, um modo eurocêntrico de contar, medir e representar o tempo. Ora, em si, o passado não é uma linha, ele condensa o todo da nossa experiência, e não é possível representá-lo senão mediante uma narrativa interessada desde os limites do presente. A linha de tempo é uma representação que contém uma narrativa sobre o passado (a vida, o tempo) construída a partir de uma experiência específica e particular do tempo, que é progressiva e evolucionista. Ela tem sido excludente e violenta, nos fazendo crer que é possível controlar a passagem do tempo, prendendo-o em uma narrativa, e que esse modo de aprisionar o tempo é universal e necessário.

A inocência e a liberdade de que falei no início deste artigo estão no fato de desconfiar inclusive do que nos parece mais natural, como a linha do tempo, e de avaliá-la como uma representação que criou uma narrativa e a sustenta até os dias atuais, como se nenhuma história e nenhum ensino pudesse abandoná-la sem, ao mesmo tempo, abandonar a própria temporalidade. Essa linha do tempo tem, em si, o racismo, o genocídio e a intolerância. Assim, busco, nesse momento de perplexidade, abandoná-la em favor de uma neutralidade asfixiante, que não me deixe respirar essas representações, esses antropomorfismos, para poder pensar como fazer uma aula de História decolonizando o tempo e me entregando a outras formas ainda não pensadas de criar relações com o passado.

Nesse sentido, penso na direção de um passado prático (WHITE, 2014), de um "dever fazer", considerando meu compromisso ético e político com o modo de fazer e de expressar. Eu penso o ensino de História como um lugar de produção conceitual que consiste em uma arte do modo de expressão, não um saber específico distante dos tais saberes acadêmicos e de toda essa luta por espaços que escondem tais noções. Se é verdade que devemos pensar que decolonizar a História e a memória implica inserir novos conteúdos, como saberes e fazeres de povos até hoje silenciados, o modo de expressão assume um papel central nesse processo, uma vez que de nada adianta, por exemplo, estabelecer para os povos africanos linhas de tempo e formas de representar o tempo adequados e criados para pensar a história europeia ou, pior ainda, o que se convencionou chamar de história universal, que, em resumo, não passa de uma redução do universo à temporalidade europeia e branca. Desse modo, talvez seja mesmo necessário pensar na aprendizagem, no modo como o encontro com o passado pode permitir ter e criar novas experiências.

É por isso que um rompimento com a colonialidade do tempo parte de uma neutralidade asfixiante - esse 
movimento me ajuda tanto no conceito do ensino de História (como ele se define em sua especificidade diante da História, da Educação, do Cinema, da Matemática) quanto na reflexão sobre como posso abandonar a narrativa e imaginar uma aula de História que encerre o em si do tempo, pronta a deixar passar diversas temporalidades e diversas formas de representá-lo. Iniciarei com a consideração de que uma sala de aula de História pode ser vista - a fim de não criar modelos, padrões ou representações temporais de antemão - como Caos.

\section{O lado de Fora - A aula de História e o malogro da narrativa}

O Caos, para Nietzsche, compreende a temporalidade mesma da natureza. Ele é uma espécie de "caráter geral do mundo".

O caráter geral do mundo, no entanto, é caos por toda a eternidade, não no sentido de ausência de necessidade, mas de ausência de ordem, divisão, forma, beleza, sabedoria e como quer que se chamem nossos antropomorfismos estéticos [...] ele não é perfeito nem belo, nem nobre, e não quer tornar-se nada disso, ele absolutamente não procura imitar o homem! Ele não é absolutamente tocado por nenhum de nossos juízos estéticos e morais! [...] (NIETZSCHE, 2001, § 109).

O caráter geral do mundo não é um segredo que se esconde por trás das coisas e de lá regula seus sentidos. O Caos incorpora a ideia de podermos continuar sendo inocentemente entregues a uma perplexidade; ele atua em nosso espírito, funcionando como um Fora (FOUCAULT, 2009) que atua desde dentro. Um Fora assubjetivo - nem psicológico, nem material, nem objetivo, nem subjetivo. Um Fora real, mas não atual. Um Fora genético. É como uma abertura, a própria abertura por onde é possível desviar das coisas, questionar ideias, furar estruturas, malograr hábitos. Esse Fora é a gênese de um pensamento, é o que torna o pensamento uma entrega ao virtual, ao inatual, a fim de malograr os ditos e os vistos e lançar os dados para experimentar as novidades.

Trata-se, portanto, de uma abertura caótica ao mundo, que "tem algo de um gosto inocente" (MEES, 2011) uma inocência diante do "jogo dos dados". Essa abertura promove uma quebra na percepção, que nos deixa como moribundos, embriagados e angustiados diante das formas, dos conceitos, como alguém com enfado com a História. Essa insensatez do momento inocente que se abre ao Fora é o Caos atuando no espírito, guiando o espírito até as profundezas da energia vital da criação (BERGSON, 2005). Pensamento e criação, então, se encontram na abertura do Caos, em um fluxo de energia vital que produz o ainda impensável, ainda inimaginável, a pura criação. 
A questão que nos envolve é justamente pensar que o Caos habita uma aula de História. Ainda que uma aula de História possa ser vista como lugar privilegiado da narrativa. Nela há formas, coisas, datas, estruturas, conjunturas, conceitos definidos... E pouco jogo. Ela mais forma do que cria. O que pretendemos é que quando há, numa aula de História, o malogro da narrativa, se torna possível um flerte dessa aula com o Caos, como o Fora, quando ocorre uma indefinição insuportável das coisas ditas, das histórias contadas e das narrativas apresentadas, permitindo uma fuga em relação à temporalidade eurocentrada.

Se observamos atentamente a sala de aula e construímos cenas a partir dela (PEREIRA; SEFFNER, 2018), nos perguntaremos a todo instante sobre o caráter de uma aula de História, como o fazem os estagiários e licenciandos. Essa pergunta pode ter inúmeras e incomensuráveis respostas. Neste artigo, como venho argumentando, penso que uma aula de História pode muito bem sentir o gosto da energia vital, que se mostra nos instantes de hesitação que nos jogam, todos, alunos, professores e conceitos, no jorro do Tempo, perdidos no Caos genético, diante do assombro da falta de narrativa e de sentido. É como um momento de hesitação diante de tudo: das descrições, das definições conceituais, das narrativas coerentes e organizadas, das subjetividades já definidas. É como estar em uma cesura do tempo, quando nem isto nem aquilo parece fazer sentido, e nos colocamos exatamente ali, onde não há isto nem aquilo; sujeito ou objeto; linha do tempo ou cronologia que possa doar sentido à vida. A experiência em uma aula de História remete a essa cesura no tempo, que cessa toda a narrativa e se abre para o inusitado e o surpreendente, a fim de encontrar "a abertura por onde vazam todas as estruturas, por onde desfalecem todos os modelos e por onde sucumbem todas as narrativas pretensiosas de verdade (PEREIRA; TORELLY, 2015).

Às vezes, quando tentamos argumentar sobre a temporalidade eurocentrada que povoa a aula de História, surgem questões do seguinte tipo: "Por que não trabalhar com a linha do tempo e, a partir dela, realizar uma reflexão sobre o tempo e mostrar que há diferentes formas de se relacionar com ele?" Ora, o que não aparece na superfície dessa questão é que as linhas do tempo e as cronologias, como já afirmamos acima, são formas de representar o tempo específicas e particulares, relacionadas à forma narrativa moderna, iluminista, teleológica, evolucionista e eurocêntrica. O modo como imaginamos o tempo e os diferentes modos como criamos formas de representá-lo são sempre particulares. Trata-se, pois, de uma política do tempo e, neste caso, do tempo histórico. O reconhecimento dessa política sugere a compreensão de que uma determinada maneira de produzir representação, de medir e de ter experiência com o tempo, se tornou universal e se cristalizou ao ponto de a confundirmos, como já argumentei, com o próprio tempo. Essa cristalização tornou os indígenas, 
4 Há uma infinidade de pesquisadores e professores do campo do ensino de História que tem se ocupado em problematizar a história europeia, a partir de diversas perspectivas teóricas, sobretudo o campo da decolonialidade. Apenas citarei alguns colegas, sabendo da existência de diversos outros. orientais e africanos os outros, estranhos ao homem ocidental, ao mesmo tempo incomensuráveis e redutíveis. A incomensurabilidade e a redutibilidade, juntas, fazem do outro aquele que não é compreendido, e que tal incompreensão é um sinal de que algo está errado ou em falta, daí a necessidade de reduzi-lo, de fazê-lo experienciar um tempo que não é seu, revestir-se com uma identidade que não é sua, mas se apresenta como universal.

Marcadores temporais como moderno, atrasado, evoluído ou contemporâneo têm sido comuns às aulas de História e, até mesmo, aos discursos sobre ensino de História, ainda que atualmente sejam questionados por pesquisadores envolvidos com o estudo das culturas e histórias dos negros, africanos e indígenas ${ }^{4}$ no Brasil. Tais marcadores nos levam a problematizar essa matriz eurocêntrica que constitui o nosso modo de pensar a temporalidade histórica e redefinir a maneira como inserimos (ao desconstituir tanto a história quadripartite quanto o evolucionismo e a linearidade que têm sido basilares nas organizações curriculares de História) uma abertura a novas temporalidades que possam aglutinar maneiras diversas de representar e experienciar o tempo. Desse modo, penso que há uma colonialidade do tempo que, tal como a colonialidade do poder, instituiu um modo particular de pensar a temporalidade como padrão universal e natural, desconsiderando outras formas como outros povos e culturas se relacionam com o tempo.

Talvez um dos entraves a essa problematização seja o argumento que afirma serem essas formas de marcar a temporalidade, como a linha do tempo e a cronologia, elementos que tornam a narrativa plausível ao entendimento dos alunos da escola básica. Essa argumentação esconde um medo do lado de Fora, um medo de expor-se ao Caos e à perplexidade. Esse medo regula e impõe um limite para a experiência histórica em sala de aula, limite representado pela narrativa histórica moderna e europeia. A submissão à linha do tempo e à cronologia implica um medo de furar os bloqueios da narrativa para encontrar o Outro, a temporalidade do Outro - ainda irreconhecível, incompreensível e incomensurável. Esse medo nos mantém nos limites de uma História Maior (PEREIRA, 2017). O pior de tudo é que fazemos isso sob o argumento de um outro temor, que é o de não entregar aos estudantes uma narrativa coerente. Supõe-se que as crianças e os jovens precisam de uma narrativa histórica coerente e que faça sentido, quando isso nada mais é do que fazê-los sempre prender o Caos em narrativa, ordenando o mundo e as experiências humanas em ficções com enredos coerentes, lógicos e com sentido, entretanto, particulares e estabelecidos através de um processo colonial.

Um duplo medo do Caos, do lado de Fora. Esse medo leva à pergunta: então eu não posso representar o outro, narrar o outro? E nós respondemos: não pode, a menos que queira prender o outro nos limites da sua representação. 
Porém, é preciso compreender que essa descoberta não paralisa ou impõe uma barreira intransponível para a aula de História. Ela apenas indica que estamos demasiadamente acostumados com nós mesmos, a ponto de sempre reduzirmos o outro à nossa narrativa coerente, e isso nos impede de experimentar modos de encontrá-lo por Fora de qualquer narrativa - não seria esta uma possibilidade de aprender com o outro em vez de desenhá-lo com os traços que nos obrigam a criar uma ficção com uma intriga plausível?

Essa impossibilidade de representar o outro, que é como criar linhas de fuga na ação representativa e linguageira, de não reduzi-lo à nossa ficção, pode ser mesmo o desafio mais profundo de uma aula de História, que pode se reconfigurar, se transfigurar e permitir que aprendamos novamente ao sentirmos perplexidade. Quem sabe isso não nos leve a ter encontros com o outro em vez de reduzi-lo ao ritual ficcional da aula de uma História Maior?

Suponhamos que possa existir, de fato, uma História Menor - daquelas que admitem temporalidades improváveis e, sobretudo, virtuais, que ainda não foram capturadas pela narrativa. Decerto que, para poder expressá-las, é necessário a perplexidade de encontros improváveis. Ela seria, então, um lugar que ainda não existe - inatual. Assim, poderia ser uma aula de História inatual, que se encontra com o inatual, que sequer habita nosso cotidiano. Que aula seria essa? Mais uma vez, o medo do Caos se expressa em uma pergunta que aproxima o sujeito de uma ânsia, quase obsessiva, pela coerência narrativa, pela organização do texto em um tom geralmente trágico, que parece dar luz ao discurso histórico. É a ânsia de explicação e de compreensão. É o medo de viver sem saber como nomear o outro, já que ele, por vezes, parece incapaz de se acomodar no interior da nossa coerente narrativa, da nossa estruturada ficção, em que consiste a narrativa histórica em sala de aula.

Assim, caso se possa pensar que há mais no mundo do que a lógica de uma narrativa colonial que o prende em sentidos e conceitos, que o mundo não se reduz aos códigos de uma linguagem, nem aos cânones de uma narrativa, nem às representações intelectuais através das quais o nomeamos e desaceleramos a velocidade infinita do Caos, aceita-se uma certa "inocência" diante do mundo - uma inocência que permite flutuar sobre os objetos e os sujeitos, sobre a objetividade e a subjetividade, sem encostar nem em uma, nem noutra, para poder dormir sem estar dormindo, em uma "vontade de nada" que nos torna puros a fim de experimentar o lado de Fora. Tal inocência marca um gosto por lugar nenhum, é como viver na inocência de um jogo à espera do "lance dos dados" e, no fim, ver que o jogo e os dados nos permitem experimentar 
o inimaginável, o impensado, o irreconhecível. A virtualidade se abre no lado de dentro, constituindo ali um Fora. Tudo se passa como se a virtualidade fosse uma abertura por Fora do objetivo e do subjetivo, inatual mas real, insinuando lançar-se a fim de esburacar o "fardo da História".

Nesse sentido, aula de História que rompe com a colonialidade do tempo pode ser uma multiplicidade sem forma predefinida, que se constitui conforme os diálogos, as negociações e as tensões que a atravessam. Desse modo, o seu segredo, aquele que ela guarda como o grande mistério que a compõe, é de não ser submissa ao modo europeu de pensar as relações entre passado e presente, sempre pronto a considerar o desenho de um presente eterno que apaga passado e futuro e que consiste justamente no que já havia dito Foucault (1989) sobre a leitura iluminista, de que o presente é o “ápice de uma evolução”. Tal concepção silencia sobre dois elementos fundamentais: o primeiro é a ideia de que, se o único tempo é o presente, então nem a experiência do passado é digna de ser lugar de aprendizagem, nem a esperança do futuro permite reservar novidades, o acontecimento incorporal seria uma impossibilidade, visto que se desdobra em reserva virtual do passado e esperança virtual do futuro (DELEUZE, 1998); o segundo é o fato de que exaurimos a dimensão ética da História, pois, ao passo que o tempo parece ter tido seu ápice, o pensamento como força política de criação de novos mundos e novas relações, deixa de ser um modo de viver. E é aí que a colonialidade do tempo parece ter seu momento mais importante de apagamento das forças selvagens que podem lhe corroer. O modo ainda cartesiano de compreender a filosofia e o conhecimento define uma distância significativa entre a aprendizagem e a espiritualidade, transformando a aprendizagem em uma faculdade técnica, preocupada com as causas e as identificações. A aula de História como Caos tem como prerrogativa a ideia de que a aprendizagem é do campo da ética e do dever ser, que ela implica uma transfiguração de quem aprende. Logo, não se trata de simplesmente aprender causas e identificar fatos distantes e frios, mas de se encontrar em abertura diante da experiência do outro, de modo a constituir novas experiências para si mesmo.

\section{O ensino de História - um modo de expressão}

O ensino de História, tal como concebemos neste artigo, está diretamente relacionado a modos de expressão. É adequado supor que, em cada lugar de enunciação dos conceitos históricos, há maneiras singulares de expressar o conhecimento histórico, bem 
5 A ideia de um lugar passivo do pensamento está relacionada a ideia de se deixar abater pela violência do lado de Fora (DELEUZE, 1988), tal como temos conceitualizado neste artigo. como há relações específicas dos conceitos com outros saberes e com práticas sociais e políticas relativas àquele lugar de enunciação. É justo supor, portanto, como já referi, que os modos de expressão e as relações são diferentes na escola, na universidade, na pós-graduação, em um programa de televisão e assim por diante. $\mathrm{O}$ que procurei argumentar foi que entendo o ensino de História e a aula de História como lugares de um encontro com o pensamento decolonizado. Nesse sentido, o que faz o ensino de História não é apenas criar nomes, designar estruturas e conjunturas; é construir modos de expressão dos conceitos históricos. Desse modo, ele é sempre um excesso em relação aos conceitos, uma vez que os modos de expressão implicam um encontro criativo com outros saberes e outras práticas no interior da aula de História, onde quer que ela ocorra.

Se o que o ensino de História faz é construir modos de expressão, então o seu lugar é o da hesitação, pois hesitar é situar-se em um intervalo de tempo, quando a identificação se torna difícil e somente o que existe é uma insistência. Esse intervalo temporal promovido pela hesitação desdobra-se em uma neutralidade, que é o lugar mesmo de uma criação e de um encontro produtivo. Ao provocar a hesitação, em um intervalo temporal que gera desidentificação em relação às formas do presente, o ensino de História permite um espaço para criar. E isso ocorre em uma aula de História, se conseguirmos olhar os alunos, os grupos, os enunciados e hesitarmos, não vendo identidades, coisas, frases ou proposições, mas forças que esperam um diálogo e uma escuta. O projeto de um movimento de combate à colonialidade do tempo necessita desse deslocamento, o que significa poder dessubjetivar-se em relação aos modos cristalizados de perceber, medir e experienciar o tempo. É isso que estou chamando de malogro da narrativa. A narrativa histórica busca compreender e explicar processos e verificar causas e efeitos, ligando o presente ao passado e ao futuro, condensando, de certa forma, as possibilidades de futuro, no presente. A suspensão dessa narrativa significa uma abertura à imaginação de mundos não previstos, não supostos, mas imaginados a partir de um lugar passivo do pensamento ${ }^{5}$.

O que estou afirmando é que a situação nesse intervalo, fruto da hesitação diante do presente, é a dimensão ética do ensino de História. Ele leva à criação e à autoconstituição de si como subjetividade em abertura (hesitante) e, então, essa hesitação lhe permite imaginar mundos ainda não catalogados pelas formas do presente. Isso quer dizer estar em abertura para outras relações temporais, outras formas de medir o tempo, mas, sobretudo, outras relações com o passado (quem sabe, uma outra definição de História) e experiências inusitadas com o tempo. 
O encontro ao substituir a redução narrativa do outro, implica uma liberdade em relação às coisas, às formas, às identificações, que possibilita a aprendizagem e a reterritorialização da própria narrativa. Suspender a narrativa, então, não quer dizer afastá-la da aula de História ou torna-la estranha ao ensino de História, mas suspendê-la, por vezes, como modo de abrir um lugar (o encontro) onde a aprendizagem com o outro se torna possível. A partir desse lugar de criação, outras narrativas e outros conceitos podem ser construídos.

Desse modo, penso que o ensino de História não é nem um objeto da transposição didática, nem uma mediação entre saberes, nem mesmo um novo saber. $O$ ensino de História não é isso ou aquilo; sua definição é uma busca estéril que demonstra um apego demasiado cientificista a um estatuto, a um lugar necessário de reconhecimento pelo culto acadêmico. Tal busca parece, inclusive, responder a um ressentimento decorrente do antigo debate sobre o ensino e a pesquisa; a história ensinada na escola e a história acadêmica. Entendo que não há duas histórias, mas há conceitos históricos ensinados e/ou comunicados em diferentes lugares de enunciação. O ensino de História não é. E o que ele faz é um duplo movimento: constrói conceitos para pensar a aula de História e seus modos de expressão, seus encontros e suas relações e constrói modos de expressão dos conceitos históricos. É como se a expressão dos conceitos históricos em sala de aula se nutrisse dessa hesitação de que tanto falo, na medida em que cria um não-lugar, uma neutralidade que, sem a prisão dos objetos ou dos sujeitos, permite a criação conceitual e os encontros que geram aprendizagem, rompendo com a operação temporal criada pela colonialidade do tempo e se abrindo a experiências alheias e estranhas.

Essa dupla função se dá em um intervalo temporal e está relacionada à ideia do Caos em uma aula de História - esta, por sua vez, pensada como uma absurda abertura por onde transitam diferentes povos, com diferentes modos de se relacionar com o passado, diferentes saberes e diferentes práticas, inclusive a História (lugar de criação conceitual). Esse trânsito só é possível se pensarmos o intervalo temporal (que implica a suspensão das formas de representar, medir e experienciar o tempo que conhecemos e através dos quais organizamos o nosso mundo), que tem a ver com a suspensão da narrativa histórica, momento no qual são possíveis encontros e criação de conceitos.

Há uma razão, portanto, para a suspensão da narrativa e, ao mesmo tempo, para retornar a criar novas narrativas. Essa razão é de caráter prático, decorrente de uma razão prática, de um dever ser (WHITE, 2014), que brota do lugar brumoso do vazio da narrativa para criar novas relações, novos mundos, novas formas de relação com o tempo, com o passado, seja na História, na narrativa oral ou na memória. Isso requer o estilhaçamento da colonialidade do tempo, a fim de abrir a aula de História para práticas, 
cosmologias, formas de vida latino-americanas, afro-brasileiras, indígenas, africanas... Cessam, portanto, o dualismo e o evolucionismo. Cessam os fundamentos de uma História moral e etnocêntrica, que julga o outro a partir de seus padrões de modelos de experienciar o tempo.

É nesse sentido que a dimensão ética (o dever ser) devolve o tempo em si, o tempo puro. Trata-se de um retorno ao "caráter geral da natureza", ao Caos, de tal forma que esse retorno concede novamente o tempo ao próprio tempo, sem que ele seja recortado, desacelerado, representado por um grupo particular que usa suas representações como se fossem o próprio tempo. Isso torna possível supor que o ensino de História se põe a pensar sobre modos de expressão que considera a aula como Caos e que mantém a potência da criação através de encontros que reservam o máximo de força e o mínimo de definição

\section{Concluo com a cena de uma aula que resiste à colonialidade do tempo}

Havia um certo temor no olhar, nos gestos e na voz trêmula dos dois professores. Entraram na sala ainda sem saber o que lhes esperava - talvez fosse sempre assim, no caso deles. Esse temor indicava que o que aconteceria em sala de aula era imprevisível; todos os dias poderiam parecer iguais, mas, para os dois, a sala de aula parecia sempre reservar um medo na forma do imprevisível. Diante dos alunos, eles anunciaram o tema: Civilização. Antes de estudar o que se convencionou chamar de Antiguidade Oriental, eles pensaram em criar uma situação de aprendizagem que permitisse debater o conceito de civilização e seus efeitos. Foi aí que a aula se mostrou realmente imprevisível, porque ela nasceu exatamente da hesitação que se insinuou naquele lugar, por entre as cadeiras, atravessando professores e alunos e, sobretudo, o próprio conceito. $O$ modo de expressão não foi uma narrativa histórica explicativa ou compreensiva. O que ali aconteceu, do ponto de vista da expressão dos conceitos históricos, foi um jogo. A aula se tornou um tabuleiro onde os lugares não estavam predeterminados, nem as jogadas predefinidas. Os professores entraram com temor, $e$ esse sentimento se ampliou como um terremoto de forças estranhas e criativas para flertar com o Caos, onde as singularidades podem dar lugar a novas formas e o conceito de civilização ainda não existe. Assim, a aula iniciou com um disparador que buscou nos estudantes as definições já sabidas sobre civilização e, imediatamente, provocou os alunos, buscando levá-los a uma outra região distanciada da realidade histórica: "Imaginem como se comportaria um povo não civilizado?"; "Existem ainda hoje povos não civilizados?"; "Imaginem um mundo onde não seja possível julgar quem é ou quem não é civilizado"... Nesse embate que fez tremer o tabuleiro, apareceu, como Alcibíades no banquete de Platão, o filme 300, e foi ele que 
6 A cena descrita foi uma livre adaptação de uma aula de estágio no Ensino Fundamental, dos alunos Gabriel Ethur e Vinícius Reis Furini, na EEEM Sarmento Leite, em Porto Alegre, em 2018/o1. Um agradecimento especial aos Gabriel e aos Vinícius pelo que pude aprender com eles. jogou todos em um turbilhão criativo até o outro conceito de "orientalismo".

Foi aí que a hesitação dos professores os levou por caminhos muito desconhecidos. Como pensar conceito tão complexo com estudantes do primeiro ano do ensino médio? Como o conceito de orientalismo pode ser criado em uma sala de aula de História da Escola Básica? Será que pode ser um conceito adequado ao mundo desses alunos do bairro Cristo Redentor? E a hesitação deu lugar, sem deixar de se insinuar, à criação e a imaginação, como poética do real, e se manteve por muito tempo, até chegar ao filme 300, uma forma fabulatória dos conceitos de Ocidente e Oriente. O jogo chegou a duvidar que esse filme pudesse dialogar com uma sala de aula que se propôs estudar conceitos tão altos. As imagens começaram a ser expostas sobre os gregos e sobre os persas, sobre o Ocidente e sobre o Oriente e, dali, daquele não lugar imaginativo, nasceu o conceito de orientalismo. E a aula continuou. Seu tempo cronológico foi sugado ao esquecimento, mas os efeitos incorporais da experiência que ali se deu, dura no Tempo. Talvez a aprendizagem mais importante tenha sido a de que hesitar é a brecha necessária a qualquer aprendizagem, a qualquer imaginação e, mais ainda, é o modo através do qual nos pomos a duvidar deste mundo e seu eterno presente. Duvidar da ideia de civilização é questionar o modo como temos medido, representado e, sobretudo, tido experiências com o tempo a partir do que nos promete a colonialidade do tempo. Ética, hesitação e intervalo temporal: eis a aula dos professores e seu temor. Medo que agora parece ser mais do hábito do que do imprevisível. Um medo-descontentamento que sugere um estranhamento em relação a si mesmo, suas crenças e seus modos de ver e dizer o mundo. ${ }^{6}$

\section{Referências}

BERGSON, Henri. A evolução criadora. São Paulo: Martins Fontes, 2005.

CHEVALLARD, Y. La Transposición Didáctica: del saber sabio al saber enseñado. Argentina: Editorial Aique, 1997.

DELEUZE, Gilles. Bergsonismo. São Paulo: Editora 34, 2012.

. Foucault. Tradução Claudia Sant'Anna Martins. 1. Ed. São Paulo: Brasiliense, 1988.

. O atual e o virtual. In: Éric Alliez. Deleuze Filosofia Virtual. (trad. Heloísa B.S. Rocha) São Paulo: Ed.34, 1996.

. Lógica do sentido. São Paulo: Perspectiva, 1998. 
FOUCAULT, Michel. O pensamento do exterior. In: Ditos e Escritos III. Estética: Literatura e Pintura, Música e Cinema. Tradução Inês Autran Dourado Barbosa. 2. ed. Rio de Janeiro: Forense Universitária, 2009.

. O que é o iluminismo. In: ESCOBAR, C. H. (Org.). Dossier Foucault. Rio de Janeiro: Taurus, 1989, p. 103-112.

MEES, Leonardo. Nietzsche e o caos como caráter geral do mundo. Revista Ítaca, n. 16, 2011.

NIETZSCHE, Friedrich. A gaia ciência. Trad. de Paulo César de Souza. São Paulo: Companhia das Letras, 2001.

- Assim falava Zaratustra. Tradução de Maria da Silva. Rio de Janeiro: Bertrand Brasil, 1989.

PELBART, Peter Pál. Vida capital: ensaios de biopolítica. São Paulo: Iluminuras, 2011.

PEREIRA, Nilton Mullet; SEFFNER, Fernando. Cenas de aulas de História: como aprender com isso?. In: GIL, Carmem Zeli de Vargas; MASSONE, Marisa Raquel. (Org.) Múltiplas vozes na formação de professores de História: experiências Brasil-Argentina. 01 ed. Porto Alegre: EST Edições, 2018, v.01, p. 49-68.

PEREIRA, Nilton Mullet. Ensino de História e resistência: notas sobre uma história menor. Revista @rquivo Brasileiro de Educação, Belo Horizonte, vol. 5, n.10, jan-abr, 2017.

PEREIRA, Nilton Mullet; TORELLY, Gabriel. O jogo e o conceito: sobre o ato criativo na aula de história. OPSIS, Catalão, v.15, n. 1, p. 88-100, 2015.

QUIJANO, Anibal. Colonialidade do poder, eurocentrismo e América Latina. In: LANDER, Edgardo. (Org.). A colonialidade do saber: eurocentrismo e ciências sociais. Perspectivas latino-americanas. Colección Sur Sur. Buenos Aires: CLACSO, 2005, p. 107-130. Disponível em: Acesso em: 20/10/2014.

Que tal raza!. In. PALERMO, Zulma y PABLO, Quintero (Compiladores). Aníbal Quijano: textos de fundación. $1^{\mathrm{a}}$ ed. Ciudad Autónoma de Buenos Aires: Del Signo, 2014.

WHITE, Hayden. The practical past. Evanston, Illinois: Northwestern University Press, 2014. 